\title{
Knowledge attitude and practice of contraceptives in married women in a tertiary care
}

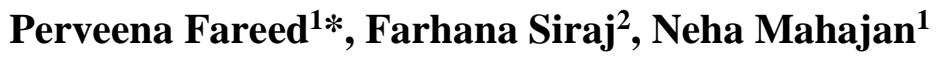

${ }^{1}$ Department of Obstetrics and Gynecology, ${ }^{2}$ Department of Medicine, GMC Srinagar Jammu and Kashmir, India

Received: 15 July 2017

Accepted: 08 August 2017

\section{*Correspondence:}

Dr. Perveena Fareed,

E-mail: perveen.fareed21@gmail.com

Copyright: (C) the author(s), publisher and licensee Medip Academy. This is an open-access article distributed under the terms of the Creative Commons Attribution Non-Commercial License, which permits unrestricted non-commercial use, distribution, and reproduction in any medium, provided the original work is properly cited.

\begin{abstract}
Background: To estimate the knowledge, attitude and practice of contraception among women attending postpartum OPD.

Methods: This cross-sectional study was conducted in Obstetrics and Gynecology outpatient department Government medical college Srinagar. Sample size of 200 patients attending post-partum OPD were taken and questioned using a questionnaire. Questions were asked regarding age, educational status, parity, knowledge, practice of contraceptives and reasons for non-use of contraceptives.

Results: $63 \%$ of patients were aware of any contraceptive. Among contraceptives most common known contraceptive was OCP's (62\%) followed by female sterilization (52\%) and Intrauterine devices (51\%). Only $21 \%$ were aware of male sterilization. Implants were known to only $5 \%$ of patients. Awareness of emergency contraceptives was seen in only $18.5 \%$ of patients. Among patients having awareness of contraceptives most common used method was OCP's (73\%) followed by barrier, IUD's (48\%) and injectable (44\%).

Conclusions: The study highlights that awareness does not always lead to the use of contraceptives. A lot of educational and motivational activities and improvement in family planning services are needed to promote the use of contraceptives and reduce the high fertility rate.
\end{abstract}

Keywords: Awareness, Contraception, Contraceptive, KAP survey

\section{INTRODUCTION}

India is the second most populous country in the world having a rapidly growing population which is currently increasing at the rate of 16 million each year. ${ }^{1}$ To slow down this growth rate, the National Population Policy was national population control programme in 2000, revised by the Government of India in 2015-2024, with the objective of bringing down the total fertility rate to the replacement level by $2024 .^{1}$

Of the world population, $75 \%$ live in developing countries characterized by high fertility rate, high maternal and infant mortality rate and low life expectancy. ${ }^{2}$
The world population will likely to increase by 2.5 billion over the next 43 years, passing from the current 6.7 billion to 9.2 billion in $2050 .^{2}$ Birth spacing not only reduce fertility but also improve health of the mother. The leading causes of death among reproductive age women are due to complications arising during pregnancy and child birth. ${ }^{3}$

Each year approximately 55,000 women die in India due to pregnancy or childbirth-related complications. ${ }^{4}$

In developing countries Couple Protection Rate (CPR) is still very less. According to national family welfare statistics 2011, CPR in India is $40.4 \%$. In Pakistan CPR 
was $30 \%$ in 2011 while most developed country like USA has $71 \%$ CPR for all methods. ${ }^{5,6}$

Now a day, fertility rate has come down due to wide spread use of family planning methods, whereas some developing countries like India, Pakistan, the use of contraception is still low because of lack of awareness, education, religion, cultural, economic and political barrier. $^{7}$

\section{METHODS}

A cross sectional study was conducted from May 2015 to Dec 2015 in Obstetrics and Gynecology outpatient department Government medical college Srinagar. Sample size of 200 patients attending post-partum OPD were taken and questioned using a questionnaire. Married women between the age 15-49 year of age and having the ability to communicate in local language served as inclusion criteria, while unmarried women were excluded due to cultural reasons. The data was collected through interview by trained obstetrics and gynecology registrar. The women interviewed were informed of the study and consent was taken. The participation was on voluntary basis. Interview with each woman lasted for 15-20 minutes. Data was recorded on a predesigned questionnaire. The questionnaire consisted of demographic characteristics including age, marital status, level of education, and employment. Questions were asked regarding previous pregnancies and family planning method used, knowledge about contraceptive methods like condoms, combined oral contraceptive pills (COC), injectable hormones, intrauterine contraceptive device (IUCD), and withdrawal method. The knowledge of permanent method of contraception like tubal ligation and vasectomy was also assessed. The source of knowledge and the women's attitude towards the contraception in the form of motivation, involvement of spouse and/or self and acceptability of contraception were recorded. Questions regarding factors responsible for non-use of contraception were also asked. Descriptive analysis was done and the results were given in percentages. SPSS 20.0 was used to analyze the data.

\section{RESULTS}

Table 1: Demographic profile.

\begin{tabular}{|c|c|c|}
\hline Parameter & Number & $\%$ \\
\hline Illiterate & 76 & 38 \\
\hline Middle & 68 & 34 \\
\hline High school & 43 & 21 \\
\hline Graduation & 23 & 11.5 \\
\hline Mean age & $28 \pm 6.5 \mathrm{yr}$ & \\
\hline \multicolumn{3}{|l|}{ Parity } \\
\hline P1 & 24 & 12 \\
\hline P2-P3 & 89 & 44.5 \\
\hline$>\mathrm{P} 3$ & 87 & 43.5 \\
\hline
\end{tabular}

A total of 200 patients attending postpartum OPD were taken for the study and questioned regarding age, parity, educational status, awareness of any contraceptives, attitude towards contraceptives and practice of any method known.

As shown in Table 1, the mean age of patients was $28+6.5 y$ rs. A significant percentage of patients were illiterate $(38 \%)$ and $34 \%$ were middle pass. $21 \%$ had passed high school and only $115 \%$ had pursued graduation. $44.4 \%$ patients were having parity between P2-P3 and $43 \%$ were >P3 and $12 \%$ of patients were primipara.

Table 2: Awareness of contraception.

\begin{tabular}{|lll|}
\hline Parameter & Number & $\%$ \\
\hline Yes & 127 & 63 \\
\hline No & 73 & 36 \\
\hline Method known & & \\
\hline Natural & $72 / 127$ & 36 \\
\hline barrier & 66 & 33 \\
\hline OCP & 125 & 62 \\
\hline Injectable & 70 & 35 \\
\hline IUD & 103 & 51.5 \\
\hline implants & 11 & 5 \\
\hline Female Sterilisation & 105 & 52 \\
\hline Male sterilization & 42 & 21 \\
\hline Emergency contraceptive & 37 & 18.5 \\
\hline
\end{tabular}

As is seen in Table 2, 63\% of patients were aware of any contraceptive. Among contraceptives most known contraceptive were Oral Contraceptive pills (62\%) followed by female sterilization (52\%) and Intrauterine devices $(51 \%)$. Injectable contraceptives were known to $35 \%$ of patients. Only $21 \%$ were aware of male sterilization. Implants were known to only $5 \%$ of patients. Awareness of emergency contraceptives was seen in only $18.5 \%$ of patients.

Table 3: Source of information.

\begin{tabular}{|lll|}
\hline Parameter & Number/127 & $\%$ \\
\hline Health centre & 56 & 44 \\
\hline TV/Radio & 21 & 16 \\
\hline Social circle & 94 & 74 \\
\hline
\end{tabular}

As obvious from Table 3, most common source of information was through social circle like friends, relatives etc. $44 \%$ of patients gained information about contraceptives through health centre like doctor, nurses, ASHA workers etc. TV/Radio was source of information in $16 \%$ of patients. As seen from Table $4,95 \%$ of patients believed that contraceptives can be used for birth spacing.

Attitude towards contraceptives in preventing pregnancy and sexually transmitted infections was seen in $69 \%$ and $24 \%$ patients respectively. 
Table 4: Attitude towards contraceptive use.

\begin{tabular}{|lll|}
\hline Parameter & Number/127 & $\%$ \\
\hline Pregnancy prevention & 88 & 69 \\
\hline STD prevention & 31 & 24 \\
\hline Birth spacing & 121 & 95 \\
\hline
\end{tabular}

Table 5: Practice of contraception.

\begin{tabular}{|lll|}
\hline Parameter & Number/127 & $\%$ \\
\hline No method & 71 & 55.9 \\
\hline Barrier & 61 & 48 \\
\hline OCP & 93 & 73 \\
\hline Injectable & 57 & 44 \\
\hline IUD & 61 & 48 \\
\hline Implant & 0 & 0 \\
\hline Sterilization (F) & 47 & 37 \\
\hline
\end{tabular}

As shown in Table 5, among 127 patients having any awareness $55.9 \%$ of patients had not used any contraceptives in their lifetime.

$54.1 \%$ of patients had used any contraceptives with some patients having used more than one type of contraceptives.

OCP's were used by $73 \%$ of patients, IUD and barrier method by $48 \%$ each and injectables by $44 \%$. Female sterilization was done in $37 \%$ of patients.

Table 6: Reason for non-practice.

\begin{tabular}{|lll|}
\hline Parameter & Number/127 & $\%$ \\
\hline Fear of side effects & 47 & 66 \\
\hline Not available & 27 & 38 \\
\hline Ignorance & 33 & 46 \\
\hline Religious belief & 36 & 50.7 \\
\hline Family pressure & 21 & 29 \\
\hline Cost factor & 15 & 21 \\
\hline Not needed & 9 & 12 \\
\hline
\end{tabular}

Table 6 shows various reasons for non-use of any contraceptives. Most common reasons were fear of side effects $(66 \%)$ followed by religious belief $(50.7 \%)$, ignorance $(46 \%)$, non-availability of contraceptives $(38 \%)$. Many patients had more than one reasons for nonuse of contraceptives.

Percentage more than $100 \%$ as many patients had knowledge attitude and practice of more than one method of contraception.

\section{DISCUSSION}

This study was conducted in Obstetrics and Gynecology department GMC Srinagar. The aim of this study was to assess the KAP gap of contraception and to assess the unmet need of contraception in patients attending tertiary care.
In present study, a significant percentage of population was illiterate $(38 \%) .34 \%$ of patients had passed middle class whereas only $11.5 \%$ patients were graduate.

Present study shows that awareness of any contraceptives was seen in 63\%. Most known method was OCP's (62\%), female sterilization (52\%) and intrauterine devices $(51.5 \%)$. Awareness of emergency contraceptives was only $18.5 \%$. In a study in New Delhi awareness was seen in more than $90 \%$ but practice of any method was seen in $59.8 \%$ of patients. ${ }^{8}$ Social circle like friends and relatives were main source of information (74\%). Health care centers were source of information in $44 \%$ of patients.

In our study, non-use of contraceptive is high (55.9\%) as compared to that in the study by Young et al ${ }^{9}(39 \%)$ and by Aneblom et al (33\%). ${ }^{10}$ Among practicing group most common method used was OCP's (73\%) followed by barrier $(48 \%)$ and injectable (44\%). $37 \%$ of patients had undergone female sterilization. Most common reason for non-use of contraceptives was fear of side effects $(66 \%)$ followed by religious belief $(50.7 \%)$, ignorance $(46 \%)$ and non- availability (38\%).

\section{CONCLUSION}

Awareness of contraceptives is low in study subjects. There is a significant contraceptives gap in awareness and practice of contraceptives. The most common reason for non- use being fear of side effects.

\section{Recommendations}

Improve female literacy rate. Increase awareness by using sustained efforts to increase awareness and motivation for contraceptive use. This can be brought about by facilitating the access to more information, education and communication with the reproductive age couples, and improved social and welfare services. Regular availability of contraceptives and adequate health care services at the peripheral level.

Funding: No funding sources

Conflict of interest: None declared

Ethical approval: The study was approved by the Institutional Ethics Committee

\section{REFERENCES}

1. Park K. Park's textbook of Preventive and Social Medicine. $17^{\text {th }}$ edn. Jabalpur. Banarasidas Bhanot; 2002:325-58.

2. Population Reference Bureau. World Population Data Sheet, 2010. Available at: http://www.prb.org/pdf10/10wpds_eng.pdf.

3. Hammad AQ, Hashmi A, Syed AR, Jamil AS, Aslam G. Contraceptive methods and factors associated with modern contraceptive in use. J Fam Reprod Health. 2010;4:41-63. 
4. Rai SK, Dasgupta R, Das MK, Singh S, Devi R, Arora NK. Determinants of utilization of services under MMJSSA scheme in Jharkhand 'client perspective': a qualitative study in a low performing state of India. Indian J Pub Health. 2011;55:252-94.

5. WHO. Reproductive health indicator-guidelines for their generation, interpretation and analysis for global monitoring. In: WHO, eds. WHO Guideline. Geneva. WHO, Reproductive Health and Research. 2006:1-63.

6. Bibi S, Memon A, Memon Z. Contraceptive knowledge and practices in two districts of Sindh Pakistan-A hospital based survey. JPMA. 2008;58:254-7.

7. Jabeen M, Gul F, Wazir F, Javed N. Knowledge, attitude and practices of Contraception in women of reproductive age. Gomal J Med Sci. 2011;9(2):2239.
8. Bhasin SK, Pant M, Metha M, Kumar S. Prevalence of usage of different contraceptive methods in East India: A cross sectional study. Indian J Community Med. 2005;30:53-5.

9. Young LK, Farguhar CM, McCowan LME. The contraceptive practice of women seeking termination of pregnancy in an Aukland clinic. NZ Med J. 1994;107:189-91.

10. Aneblom G, Larsson M, Odlind V. Knowledge, use and attitudes towards emergency contraceptive pills among Swedish women presenting for induced abortion. BJOG. 2002;109:155-60.

Cite this article as: Fareed P, Siraj F, Mahajan N.

Knowledge attitude and practice of contraceptives in married women in a tertiary care. Int J Reprod Contracept Obstet Gynecol 2017;6:4102-5. 